PROC. OF JSCE

No. 301, Sept. 1980

\title{
IN-PLANE BEHAVIOR OF TRUSS GIRDERS \\ IN THE ULTIMATE STATE
}

\author{
By Shigeru KURANISHI*
}

\section{INTRODUCTION}

The ultimate strength of truss girders is usually regarded to be governed by the strength of the individual members. Therefore, in the case of the hinge connection of the members, the strength will depend on the column strength of a most compressed member which is simply supported and centrally loaded. But, when truss members are rigidly connected each other, the members are subjected to the elastic or plastic retraint and forced to the end rotations by the interaction of the deflection of the adjoining members and deformation as a whole structure $^{2)}$. In such a state, the ultimate strength of the individual members can not be predicted by the strength of the simply supported and centrally loaded independent columns ${ }^{3}$ ) but by many other structural conditions.

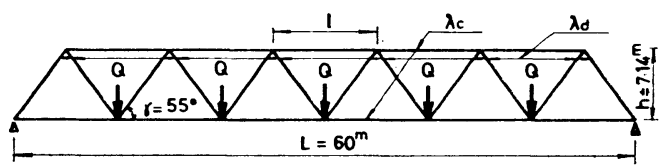

Fig. 1 Configuration of truss girder and loading

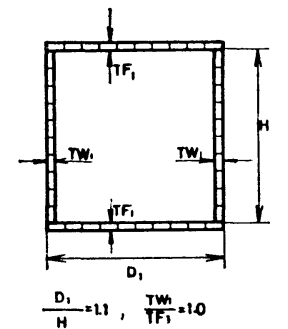

Chord Menter

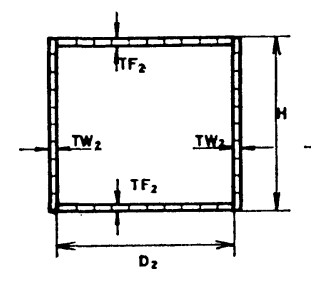

$D_{2}=D_{1}-2 T W_{2}, \frac{T W_{2}}{T F_{2}} \times 1.0$

Compression Diagonal Member

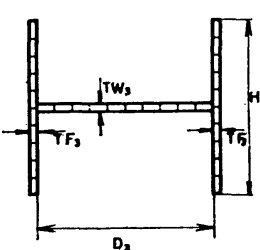

$D_{3}=D_{1}-2 \pi W_{3}, \frac{T W_{3}}{T F_{3}}=0.5$ Tension Diagonal Member
Fig. 2 Proportions of cross sections

* Member of JSCE, Dr. Eng., Professor, Dept. of Civil Eng., Tohoku Univ.

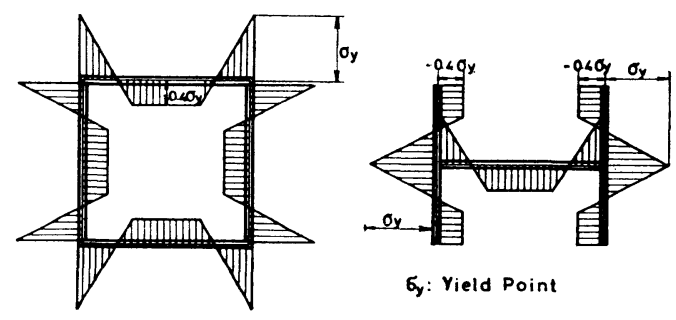

Fig. 3 Distribution of residual stresses

To get general knowledge of such a behavior of truss girders in the ultimate state, some results of numerical ultimate strength analysis is reported in this paper. Truss girders taken up here for the first step of a case study are the Warren type and have a span length of $60 \mathrm{~m}$, a height of $7.14 \mathrm{~m}$ and 6 panels as shown in Fig. 1. The chord members and compressive diagonal members have box sections and the tensile diagonal members have $\mathrm{H}$ sections (Fig. 2).

The slenderness ratio $\lambda_{c}$ of all chord members is constant and taken as 50 or 80 and the ratios $\lambda_{d}$ of all the diagonal members are also equal and varied from the value of the chord members to 150 respectively to investigate the effect of the stiffness of diagonal members on the strength of truss girders. The residual stresses (Fig. 3) and initial crookedness of $0.001 l$ are considered to know the influence.

The ultimate strength is analysed here by the combined use of the linear incremental load method and the Newton Raphson method which are fundamentally the same as adopted in the Ref. 1).

One member is divided into four member elements and a certain number of sectional segments as shown in Fig. 2. 


\section{RESULTS OF NUMERICAL COMPUTA- TION}

\section{(1) Elastic analysis}

Fig. 4 shows the load-deflection curves of the middle points of a center upper chord member obtained by the elastic non-linear analysis.

The ordinate is non-dimensionally expressed by the ratio of the loads $Q$ to the loads $Q_{E}$ which produce Euler buckling force in the center upper chord member by the first order elastic analysis.

When the slenderness ratio of the diagonal members is 50 or 80 , three deflection modes appears during the progress of large deflection in this calculated range. The each incremental modes are shown in Fig. 5 for the case of $\lambda_{a}=80$. The number of modes becomes two for a higher slenderness ratio of diagonal members as seen in Fig. 5 for the case of $\lambda_{d}=120$.

Fig. 6 shows the relationship between the load

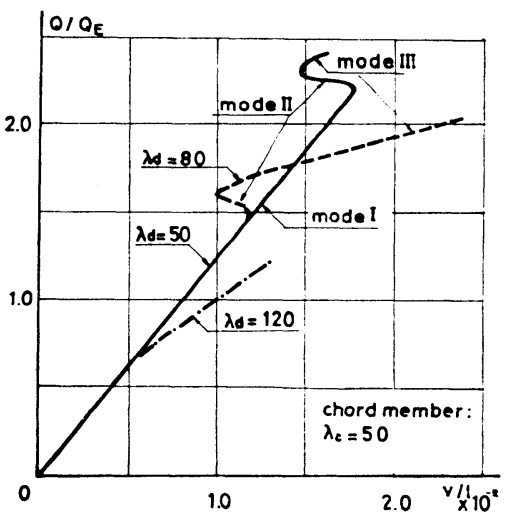

Fig. 4 Load-deflection curve at the center pt. of center upper chord member

and member forces. Corresponding each mode, each curve varies its slop. Note that the stress of diagonal member $D_{5}$ and $D_{6}$ changes its sign from

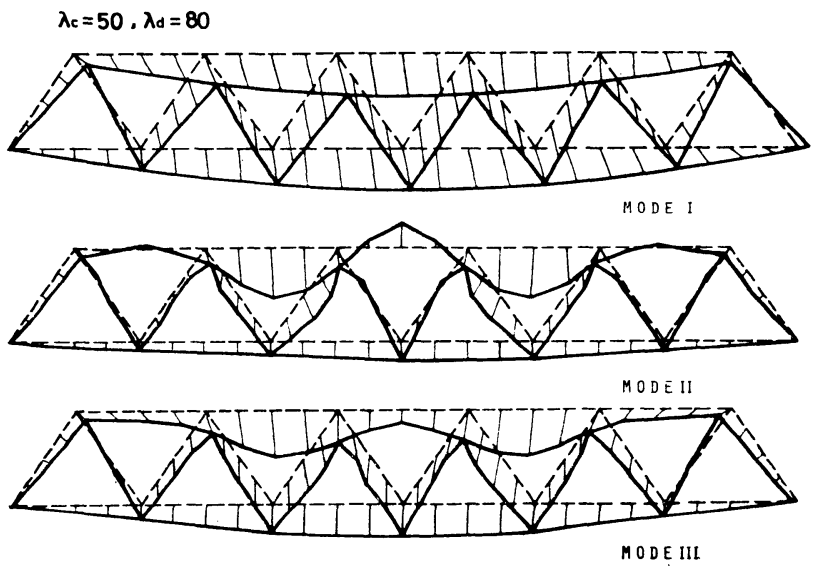

Fig. 5 Incremental deflection mode

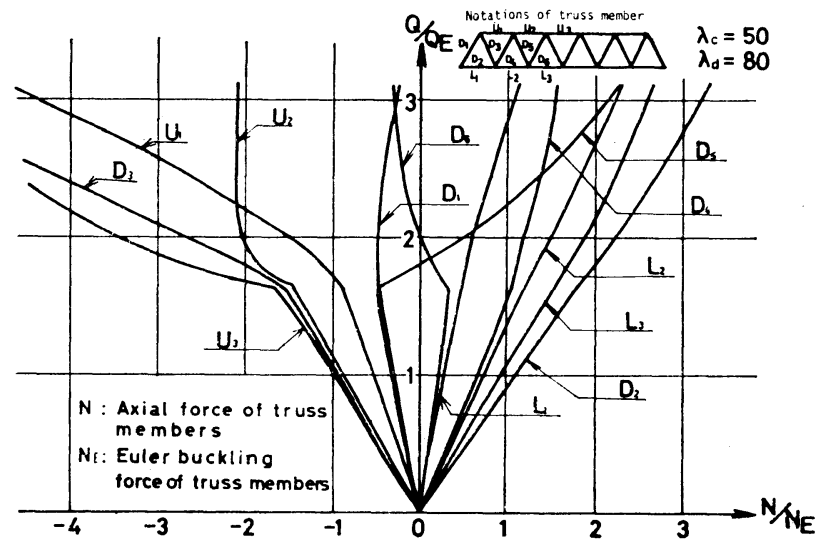

Fig. 6 Load vs. axial forces relationship by the elastic non-linear analysis 
tension to compression and vice versa. Generally speaking, by the elastic non-linear analysis, the load carrying capacity of truss girders increases to an unlimited extend with increment of loads.

\section{(2) Ultimate strength analysis}

If the influence of the plastification of material is taken into account, the increment of the deflec-

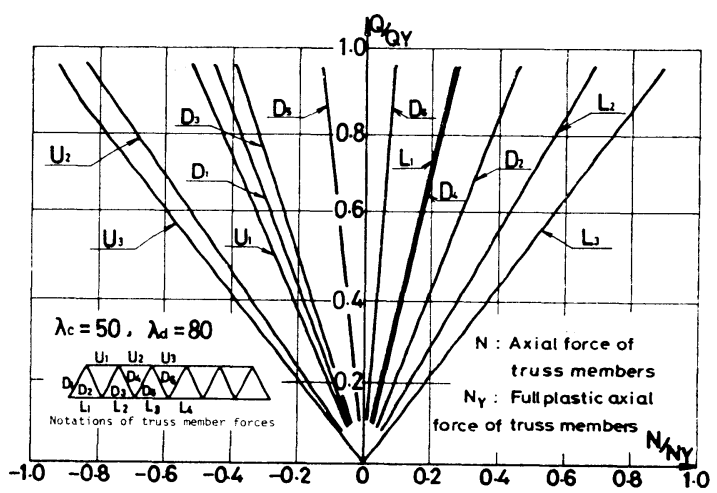

Fig. 7 Load vs. axial forces relationship by the ultimate strength analysis

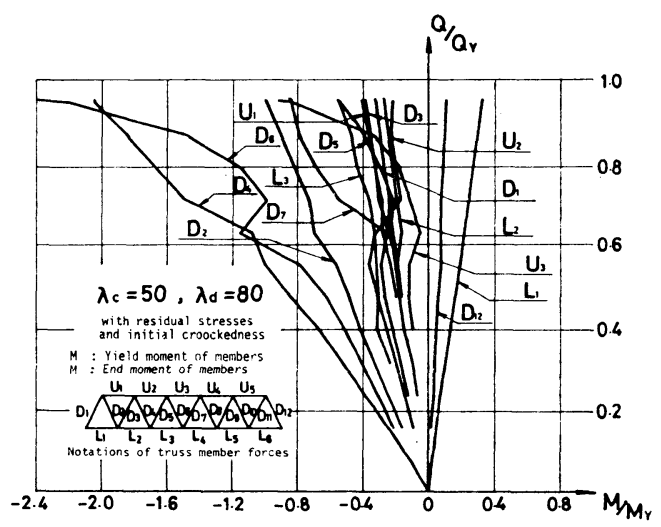

Fig. 8 Load vs. secondary moments relationship tion becomes monotonous. But, the center upper chord member itself deflects at first upward as seen in the elastic analysis and varies downward subsequently. This tendency may explain the zig.zag change of secondary moments as seen after.

The relationship between the magnitude of loads and the axial force of members becomes generally almost linear up to the nearly ultimate state as shown in Fig. 7 for the case of $\lambda_{c}=50$ and $\lambda_{d}=80$ as an example. The ordinate is expressed by the ratio of the magnitude of loads to the loads $Q_{Y}$ which produce a full plastic axial force to the center upper chord member by the 1st order elastic analysis. The abscissa is also given by the ratio $N / N_{Y}$ in which $N_{Y}$ is the full plastic axial force of members. In the numerical computation, $\sigma_{y}$ is taken as $3200 \mathrm{~kg} / \mathrm{cm}^{2}\left(314 \mathrm{MN} / \mathrm{m}^{2}\right)$. So that the slenderness parameter becomes about 0.63 and 1.0 for $\lambda_{a}=50$ and 80 respectively. But the secondary moments vary their magnitude very intricately with increment of loads as shown in Fig. 8 for example, in which they are given by the values of the left side end of members.

The influence of the flexual stiffness of diagonal members on the relative magnitude of the secondary moments is plotted in Fig. 9. In general, the magnitude becomes more significant for the centrally located diagonal members and increases with reduction of the flexual stiffness of diagonal members affected by the large deflection in the ultimate state. Fig. 10 shows the difference of the deflected configurations in the nearly ultimate state for cases of $\lambda_{c}=80, \lambda_{d}=80$ and $\lambda_{c}=$ $80, \lambda_{d}=150$.

The maximum load is plotted vs. the flexual stiffness of diagonal members in Fig. 11 in which an investigation of the influence of the residual stresses, initial crookedness and inclination angle of diagonal members are carried out. The case in which the residual stresses are not considered is not potted because of a very small difference

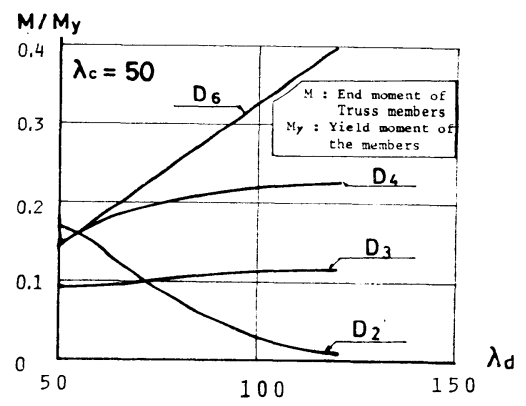

Fig. 9 Influence of the flexual stiffness of diagonal members on the secondary moments
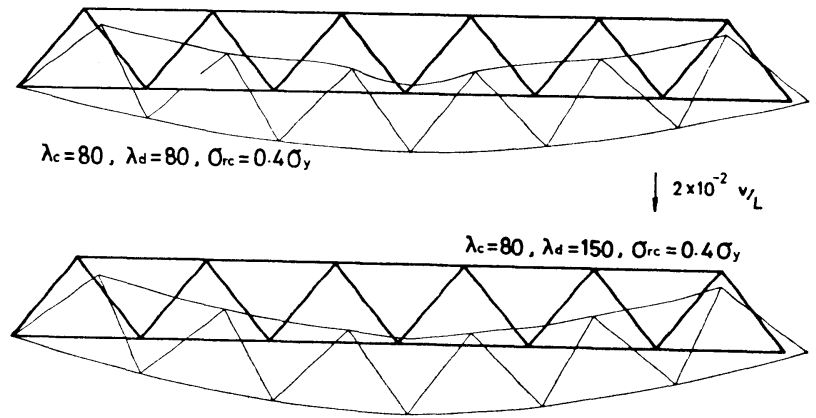

Fig. 10 Deflected comfigurations in the nearly ultimate state 


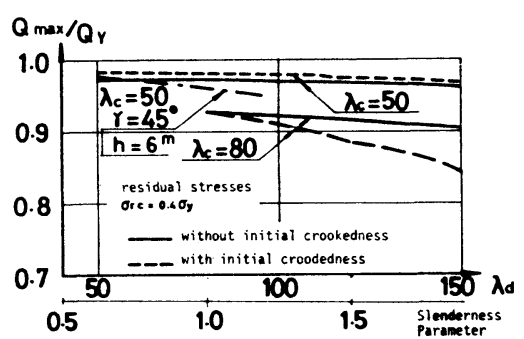

Fig. 11 Maximum load vs. the flexual stiffness of diagonal members relationship

between considered and not considered. The influence of the initial crookedness depends also on its pattern. Generally speaking, it will be recognised that the influence of these parameters taken up here is rather insignificant except for the case of very high slenderness ratio of diagonal members.

\section{CONCLUSION}

Numerical analysis were carried out to study the characteristics of the behavior of truss girders in the ultimate state by taking up some structural parameters. The following conclusion may be drawn from the results obtained in the computed range.

(1) By the elastic non-linear analysis, a certain number of deflection mode is appeared in the incremental process of loads and the load carrying capacity increases consistently with increment of deflections.

(2) Affected by the restrainment of adjoining members, the compressive strength of chord members becomes very significant and reaches almost the full plastic state except for the cases of the very small flexual stiffness of diagonal members.

(3) The influence of the residual stresses, initial crookedness and inclination angle of diagonal members on the strength of truss girders is insignificant except for the extreme cases.
(4) The relative secondary moment of diagonal members becomes large with reduction of their flexual stiffness.

\section{ACKNOWLEDGMENTS}

Appreciation is expressed to the members of the bridge engineering laboratory of Tohoku University, especially Assistant T. Yabuki, graduate student M. Otsuki and undergraduate student U. Kinoshita for their help in carrying out the computation, Miss S. Moro prepared the drawing and typed the manuscript. The computations were performed using NEAC-ACOS 700/900 computer of Tohoku University.

\section{NOTATIONS}

$v$ : Vertical deflection

$v_{c}$ : Vertical deflection of the center of a center upper chord member

$L$ : Span length

$l$ : Length of member

$\lambda_{c}$ : Slenderness ratio of chord member

$\lambda_{d}$ : Slenderness ratio of diagonal member

$Q$ : Load applied at lower panel points

$N$ : Axial compressive force of member

$M$ : Secondary moment at the left side of member

$M_{y}$ : Yield moment of member

\section{REFERENCES}

1) Kuranishi, S. and T. Yabuki: Some numerical estimation of in-plane strength of two hinged steel arches, Proc. of JSCE. No. 287, 1979.

2) Chu: Secondary moments, end rotations, inflection points and elastic buckling loads of truss members, IABSE Pub., 1959.

3) Johnstn et al.: Guide to stability design criteria for metal structures, 3rd ed. WileyInterscience 1976.

(Received Oct. 23, 1979) 